\section{(6) OPEN ACCESS}

\title{
MRI assessment of suppression of structural damage in patients with rheumatoid arthritis receiving rituximab: results from the randomised, placebo-controlled, double-blind RA-SCORE study
}

\author{
Charles Peterfy, ${ }^{1}$ Paul Emery, ${ }^{2}$ Paul P Tak, ${ }^{3 *}$ Mikkel Østergaard, ${ }^{4}$ Julie DiCarlo, ${ }^{1}$ \\ Kati Otsa, ${ }^{5}$ Federico Navarro Sarabia, ${ }^{6}$ Karel Pavelka, ${ }^{7}$ Marie-Agnes Bagnard, ${ }^{8}$ \\ Lykke Hinsch Gylvin, ${ }^{8}$ Corrado Bernasconi, ${ }^{8}$ Annarita Gabriele ${ }^{8}$
}

\begin{abstract}
Handling editor Tore K Kvien
- Additional material is published online only. To view please visit the journal online (http://dx.doi.org/10.1136/ annrheumdis-2014-206015).

For numbered affiliations see end of article.

\section{Correspondence to} Professor Charles Peterfy, Spire Sciences, Inc., 5314 Boca Marina Circle North, Boca Raton, FL 33487, USA; charles.peterfy@spiresciences. com
\end{abstract}

Received 30 May 2014 Revised 24 September 2014 Accepted 5 October 2014 Published Online First 29 October 2014

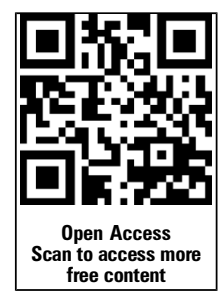

CrossMark

\footnotetext{
To cite: Peterfy C, Emery $P$, Tak PP, et al. Ann Rheum Dis 2016;75:170-177.
}

\section{ABSTRACT}

Objective To evaluate changes in structural damage and joint inflammation assessed by MRI following rituximab treatment in a Phase 3 study of patients with active rheumatoid arthritis (RA) despite methotrexate (MTX) who were naive to biological therapy.

Methods Patients were randomised to receive two infusions of placebo $(n=63)$, rituximab $500 \mathrm{mg}(n=62)$, or rituximab $1000 \mathrm{mg}(n=60)$ intravenously on days 1 and 15. MRI scans and radiographs of the most inflamed hand and wrist were acquired at baseline, weeks 12 (MRI only), 24 and 52. The primary end point was the change in MRI erosion score from baseline at week 24.

Results Patients treated with rituximab demonstrated significantly less progression in the mean MRI erosion score compared with those treated with placebo at weeks $24(0.47,0.18$ and 1.60 , respectively, $p=0.003$ and $p=0.001$ for the two rituximab doses vs placebo) and $52(-0.30,0.11$ and 3.02, respectively; $p<0.001$ and $p<0.001)$. Cartilage loss at 52 weeks was significantly reduced in the rituximab group compared with the placebo group. Other secondary end points of synovitis and osteitis improved significantly with rituximab compared with placebo as early as 12 weeks and improved further at weeks 24 and 52.

Conclusions This study demonstrated that rituximab significantly reduced erosion and cartilage loss at week 24 and week 52 in MTX-inadequate responder patients with active RA, suggesting that MRI is a valuable tool for assessing inflammatory and structural damage in patients with established RA receiving rituximab.

Trial registration number NCT00578305

\section{INTRODUCTION}

Inhibition of structural joint damage is a primary goal of rheumatoid arthritis (RA) therapy, and a number of disease-modifying antirheumatic drugs (DMARDs), including rituximab, have demonstrated this ability. ${ }^{1-5}$ While assessment of structural damage has traditionally been performed using radiography, the importance of earlier and more sensitive joint imaging has been recognised by recent guidelines. ${ }^{167}$

Although more expensive than radiography, MRI can simultaneously assess all relevant structures in the inflamed joint and is more sensitive at detecting bone erosions, allowing for smaller and shorter clinical trials. ${ }^{6} \quad 7$ Furthermore, MRI visualises articular cartilage loss directly, whereas radiography evaluates cartilage loss indirectly through jointspace narrowing. MRI can also detect joint inflammation, which is particularly useful when assessing early or undifferentiated joint disease. ${ }^{89}$

Rituximab is approved in the European Union and the USA for the treatment of RA after inadequate response (IR) to $\geq 1$ tumour necrosis factor (TNF) inhibitor. The approved dose of rituximab for the treatment of RA is two 1000-mg intravenous infusions separated by 2 weeks every 24 weeks or based on clinical evaluation, but not sooner than every 16 weeks. Rituximab inhibits joint damage progression in the indicated patient population, those with an IR to anti-TNF therapies (TNF-IR), and non-indicated populations. ${ }^{2} 310$

This study evaluated changes in structural damage and joint inflammation assessed by MRI following rituximab treatment in patients with active RA despite methotrexate (MTX) who were naive to biological therapy.

\section{METHODS}

\section{Study design and patients}

RA-SCORE was a phase $3 \mathrm{~b}$, randomised, placebocontrolled, double-blind, multicentre, international study. Patients met the American College of Rheumatology (ACR) criteria for RA with a disease duration $\geq 3$ months and $\leq 10$ years, had active RA (Disease Activity Score in 28 joints (DAS28) C reactive protein score $\geq 3.2$ ), and had experienced an IR to MTX (MTX-IR) at a dose of $12.5-25 \mathrm{mg} /$ week for $\geq 12$ weeks, with the last 4 weeks before baseline maintained at a stable dose. Minimal MTX doses of $7.5 \mathrm{mg} /$ week or $10 \mathrm{mg} /$ week were permitted only in cases of documented intolerance to higher doses. Patients were biological naive and were either positive for anticyclic citrullinated protein $(\geq 20 \mathrm{U})$ or for rheumatoid factor $(\geq 20 \mathrm{IU} / \mathrm{mL})$. Patients were also required to have erosion and/or clinical signs and symptoms of synovitis in a single (MRI) joint (metacarpophalangeal and/or wrist). In patients with a disease duration of $>1$ year, clinical evidence of synovitis and $\geq 1$ definitive radiographic erosion 
at screening based on central review were required. In those with disease duration of $\leq 1$ year, clinical synovitis needed to be confirmed by MRI at baseline. Key exclusion criteria included a history of rheumatic autoimmune disease other than RA or significant systemic involvement secondary to RA. Secondary Sjögren's syndrome and secondary limited cutaneous vasculitis with RA were permitted.

Patients were randomised in a 1:1:1: ratio to receive two infusions of placebo, rituximab $500 \mathrm{mg}$, or rituximab $1000 \mathrm{mg}$ intravenously on days 1 and 15. Premedication with analgesics, antihistamines and intravenous methylprednisolone $100 \mathrm{mg}$ were required before each rituximab infusion. Patients continued to receive stable doses of MTX and folic acid/folate ( $\geq 5 \mathrm{mg} /$ week). Concomitant oral glucocorticoids (at a stable dose $\leq 10 \mathrm{mg} /$ day) were allowed; intra-articular glucocorticoid injections could be used in a limited fashion to treat severe RA flares. Rescue therapy, or increased dose of MTX or use of nonbiological DMARDs, was permitted at week 16 for patients with $<20 \%$ improvement in tender and swollen joint counts compared with baseline. Rituximab retreatment was permitted after week 24 if patients had a DAS28 C reactive protein score $\geq 2.6$ and no contraindications to treatment (such as active infections).

This study was conducted in accordance with the Declaration of Helsinki and the International Conference on Harmonisation Harmonised Tripartite Guideline for Good Clinical Practice (NCT00578305). The protocol and any accompanying material provided to the patient were approved by an Independent Ethics Committee or Institutional Review Board before starting the study. Patients provided written informed consent before enrolment.

\section{Efficacy assessments}

Patients returned for efficacy and safety assessments at weeks 4, 6, 12, 16, 24, 36, 44 and 52. MRI scans and radiographs were acquired at baseline (within 14 days before the first study medication infusion) and at weeks 12 (MRI only), 24 and 52. The most clinically inflamed hand and wrist (or the dominant hand, in case of equal inflammation) were imaged with a 1.5 -Tesla whole-body MRI scanner using a commercial surface coil and an acrylic frame ${ }^{11}$ designed to ensure proper and reproducible positioning of the hand and wrist. The hand and wrist were scanned separately using coronal short-tau inversion recovery and coronal fat-suppressed three-dimensional gradient echo with and without intravenous gadolinium-based contrast agent. The same hand and wrist were used for all assessments.

All images were scored centrally by two independent radiologists who were blind to treatment allocations, clinical information and the order in which serial images were acquired. MRI images were scored using the Outcome Measures in Rheumatology Clinical Trials RA MRI Scoring (RAMRIS) method. ${ }^{6}{ }^{12-14}$ Cartilage loss determined by MRI was assessed using a previously validated 9-point cartilage loss scale (CARLOS). ${ }^{11}{ }^{15}$ Radiographs of hands and both feet were scored using the Genant-modified Sharp method. ${ }^{16}$

No progression was defined as a change from baseline in the RAMRIS erosion score of $\leq 0$. Total damage scores were calculated using the following formula: RAMRIS erosion score $+(2.5 \times$ CARLOS $){ }^{15}$ Total inflammation scores were calculated using the following formula: RAMRIS osteitis score $+(3 \times$ RAMRIS synovitis score $)$.

Clinical efficacy parameters included ACR 20/50/70 and European League Against Rheumatism (EULAR) response rates and change from baseline in the DAS28-erythrocyte sedimentation rate (DAS28-ESR) and in the Health Assessment Questionnaire Disability Index (HAQ-DI). Safety parameters included treatment-emergent adverse events (AEs), clinical laboratory parameters, and human antichimeric antibody (HACA) to rituximab at week 24.

\section{Statistical analyses}

The intent-to-treat population was defined as all patients who were randomised and received any part of an infusion, with analysis groups defined according to randomisation. The safety population included all patients who received any part of an infusion, analysed according to the treatment received. Additional details are provided in online supplementary text 1 .

In the primary analysis, the change in RAMRIS erosion score from baseline at week 24 (primary end point) was compared between patients receiving rituximab $1000 \mathrm{mg}$ and those receiving placebo. Secondary end points included changes from baseline in the RAMRIS erosion score at weeks 12 and 52; RAMRIS synovitis and osteitis at weeks 12, 24 and 52; and proportions of patients with no progression in RAMRIS erosion score at weeks 24 and 52. Post hoc analyses evaluated for total inflammation scores at weeks 12, 24 and 52 and change in CARLOS and total damage scores at weeks 24 and 52 .

The van Elteren test stratified for the factors used at randomisation (duration of MTX use $<$ or $\geq 6$ months and presence of bone erosions) was used for the primary analysis and to assess changes from baseline in RAMRIS erosion scores, Genant-modified Sharp radiographic erosion scores and CARLOS (imputation by linear extrapolation), and to assess changes from baseline in RAMRIS synovitis and osteitis scores (last observation carried forward). The Cochran-Mantel-Haenszel test was used to assess the proportions of patients with no newly eroded joints (no imputation used), of patients with no progression of erosions, of patients with improvements in synovitis and osteitis, and of patients

Table 1 Patient demographics and characteristics (safety population) at baseline

\begin{tabular}{|c|c|c|c|}
\hline & $\begin{array}{l}\text { Placebo } \\
+ \text { MTX } \\
\text { (n=63) }\end{array}$ & $\begin{array}{l}\text { Rituximab } \\
500 \mathrm{mg}+\mathrm{MTX} \\
(\mathrm{n}=62)\end{array}$ & $\begin{array}{l}\text { Rituximab } \\
1000 \mathrm{mg} \\
+ \text { MTX }(\mathrm{n}=60)\end{array}$ \\
\hline Female, $n(\%)$ & $48(76.2)$ & $45(72.6)$ & $50(83.3)$ \\
\hline Age, mean (SD), years & $50.3(11.9)$ & $48.7(11.1)$ & $50.7(11.7)$ \\
\hline RA duration, mean (SD), years & $4.4(3.1)$ & $4.5(2.9)$ & $4.9(2.9)$ \\
\hline MTX dose, mean (SD), mg/wk & $16.8(3.3)$ & $15.8(4.0)$ & $15.2(3.5)$ \\
\hline Concomitant CS, n (\%) & $35(55.6)$ & $33(53.2)$ & $35(58.3)$ \\
\hline SJC, mean (SD) & $11.4(6.1)$ & $12.5(7.1)$ & $10.9(5.9)$ \\
\hline TJC, mean (SD) & $14.9(6.7)$ & $15.2(7.5)$ & $14.0(6.9)$ \\
\hline DAS28-CRP, mean (SD) & $5.6(1.1)$ & $5.6(1.1)$ & $5.3(1.0)$ \\
\hline DAS28-ESR, mean (SD) & $6.3(1.1)$ & $6.3(1.2)$ & $6.0(1.1)$ \\
\hline HAQ-DI, mean (SD) & $1.5(0.8)$ & $1.4(0.7)$ & $1.3(0.7)$ \\
\hline RAMRIS erosion score, mean (SD) & $14.1(13.4)$ & $13.2(12.0)$ & $12.7(12.0)$ \\
\hline CARLOS, mean (SD) & $5.9(9.4)$ & $8.1(10.4)$ & $7.8(10.9)$ \\
\hline RAMRIS synovitis score, mean (SD) & $7.4(4.8)$ & $7.9(4.0)$ & $8.1(4.9)$ \\
\hline RAMRIS osteitis score, mean (SD) & $6.1(6.7)$ & $8.8(9.0)$ & $6.8(8.3)$ \\
\hline $\begin{array}{l}\text { Total Genant-modified Sharp } \\
\text { radiographic score, mean (SD) }\end{array}$ & $20.2(18.9)$ & $17.9(16.6)$ & $19.8(18.8)$ \\
\hline $\begin{array}{l}\text { Annualised radiographic } \\
\text { progression rate, mean (SD) }\end{array}$ & $6.3(6.7)$ & $6.8(8.9)$ & $5.7(7.4)$ \\
\hline \multicolumn{4}{|c|}{$\begin{array}{l}\text { CARLOS, cartilage loss score; CRP, C reactive protein; CS, corticosteroids; DAS28, } \\
\text { Disease Activity Score in } 28 \text { joints; ESR, erythrocyte sedimentation rate; HAQ-DI, } \\
\text { Health Assessment Questionnaire Disability Index; MTX, methotrexate; RA, } \\
\text { rheumatoid arthritis; RAMRIS, RA MRI Scoring; SJC, swollen joint count; TJC, tender } \\
\text { joint count. }\end{array}$} \\
\hline
\end{tabular}

Peterfy C, et al. Ann Rheum Dis 2016;75:170-177. doi:10.1136/annrheumdis-2014-206015 
achieving a EULAR and ACR 20/50/70 response (non-responder imputation). Analysis of covariance was used to assess changes from baseline in DAS28-ESR and HAQ-DI (last observation carried forward). All tests were two-sided and were conducted at the $5 \%$ significance level without correction for multiplicity.

\section{RESULTS}

\section{Patient disposition and baseline characteristics}

A total of 283 patients from 37 centres in 17 countries were screened. Of these, 185 patients were randomised and received study drug and were therefore included in the intent-to-treat and safety populations (19 November 2007 to 12 April 2010 from first patient randomised to last patient visit). Of the patients receiving placebo, $22 \%$ failed to complete the study, compared with $5 \%$ and $7 \%$ of patients receiving rituximab $500 \mathrm{mg}$ and rituximab $1000 \mathrm{mg}$, respectively.
The predominant reasons for withdrawal in all treatment groups were non-safety related (see online supplementary table S1). Patient disposition is shown in online supplementary figure S1. The proportion of patients who remained in the study until week 52 was higher in the rituximab groups than in the placebo group.

Baseline demographics and disease characteristics were generally well balanced among the treatment groups (table 1). The mean age of the patients was 50 years, and the mean disease duration was slightly less than 5 years. At baseline, the mean DAS28-ESR was 6.2. Patients were receiving a mean MTX dose of $>15 \mathrm{mg} /$ week, and slightly more than half were receiving concomitant corticosteroids. Approximately 77\% (48/62) and $72 \%(43 / 60)$ of patients in the rituximab 500-mg and rituximab 1000-mg groups, respectively, were retreated with a second cycle of rituximab after 24 weeks.

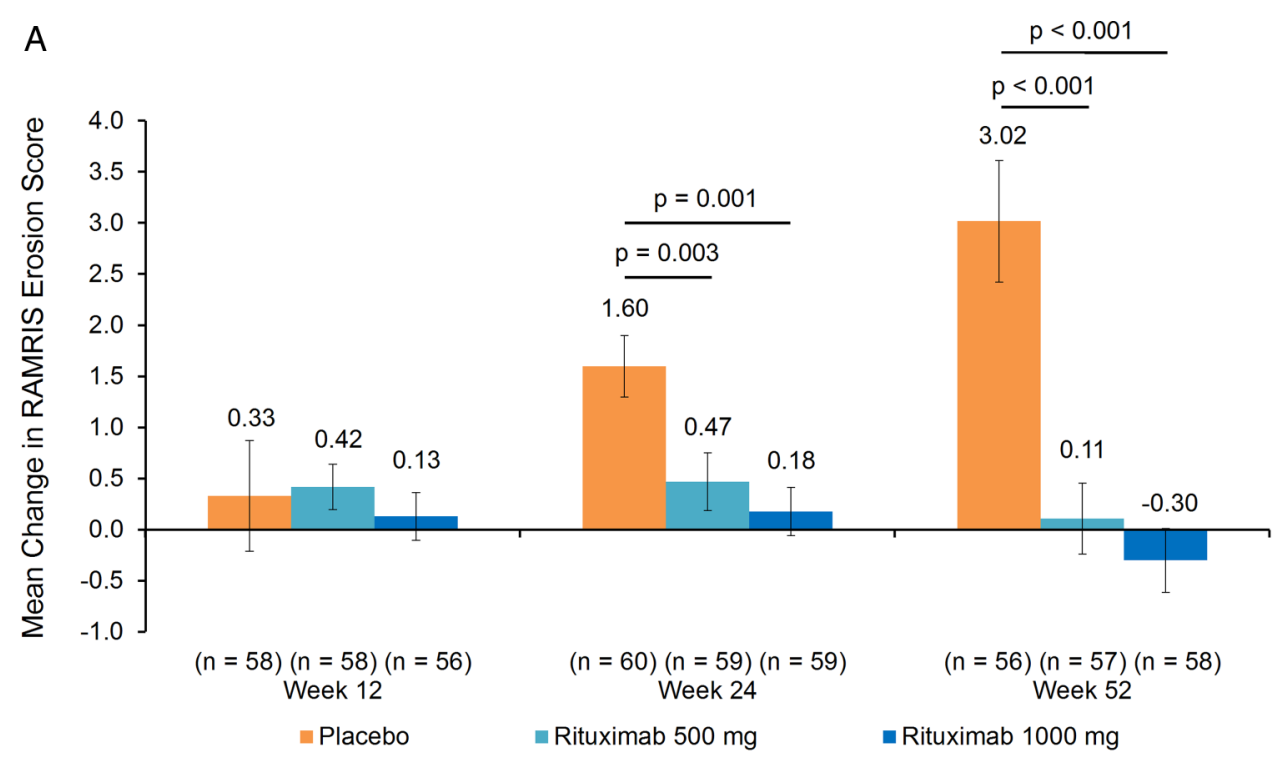

B

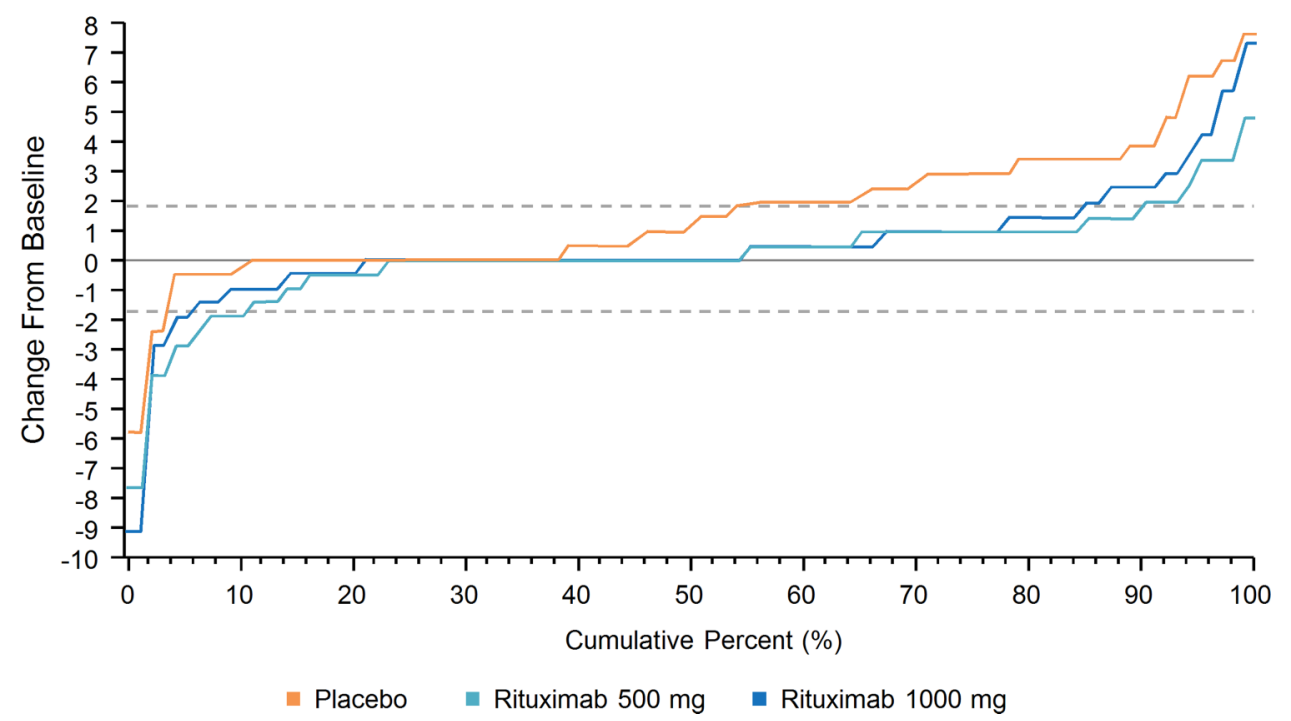

Figure 1 Primary end point. (A) Mean change in rheumatoid arthritis MRI Scoring (RAMRIS) erosion score (intent-to-treat (ITT) population). Missing values were imputed using linear extrapolation. Error bars represent the SE of the mean. (B) Cumulative distribution of change in RAMRIS erosion score at week 24. Missing values were imputed using linear extrapolation, ITT population. Broken horizontal lines represent \pm SDC (smallest detectable change, determined according to the method of Bruynesteyn, et al. ${ }^{24}$ SDCs were 1.88 for RAMRIS erosion score, 1.54 for CARLOS, 2.11 for RAMRIS osteitis score and 1.56 for RAMRIS synovitis score). 

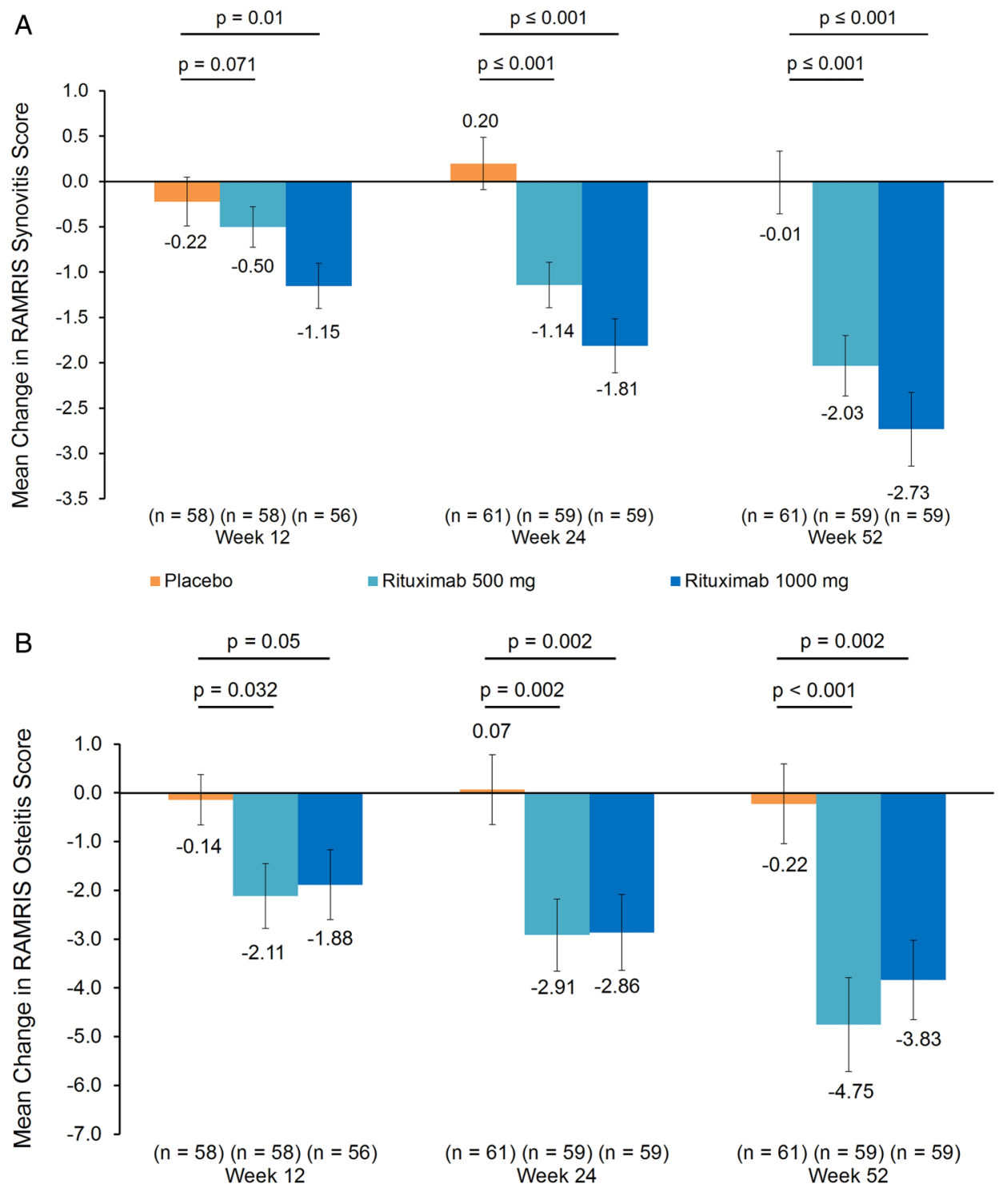

- Placebo $\quad$ Rituximab $500 \mathrm{mg}$ Rituximab $1000 \mathrm{mg}$

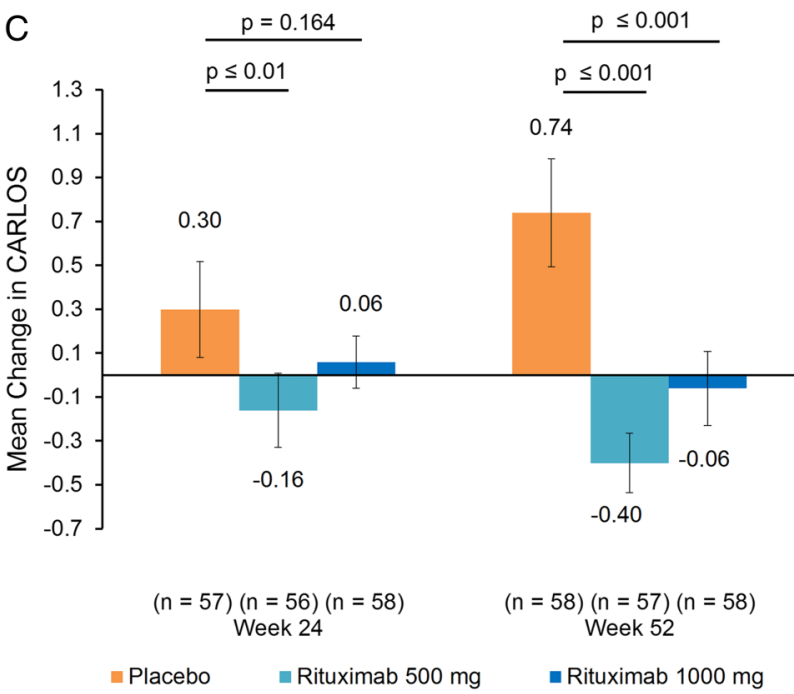

Figure 2 Mean changes in rheumatoid arthritis MRI Scoring (RAMRIS) synovitis, RAMRIS osteitis and MRI cartilage loss Score (CARLOS) (intent-to-treat population). (A) Synovitis. Missing values were imputed using last observation carried forward. Error bars represent the SE of the mean. (B) Osteitis. Missing values were imputed using last observation carried forward. Error bars represent the SE of the mean. (C) Cartilage loss. Error bars represent the SE of the mean. 
Figure 3 Mean change in total damage and total inflammation scores. (A) Total damage score. Total damage score $=$ erosion score $+(2.5 \times$ cartilage loss score). Missing values were imputed using linear extrapolation using baseline and week 12 images. Error bars represent the SE of the mean. (B) Total inflammation score. Total inflammation score $=0$ steitis score+(3xsynovitis score). Missing values were imputed using linear extrapolation using baseline and week 12 images. Error bars represent the SE of the mean.

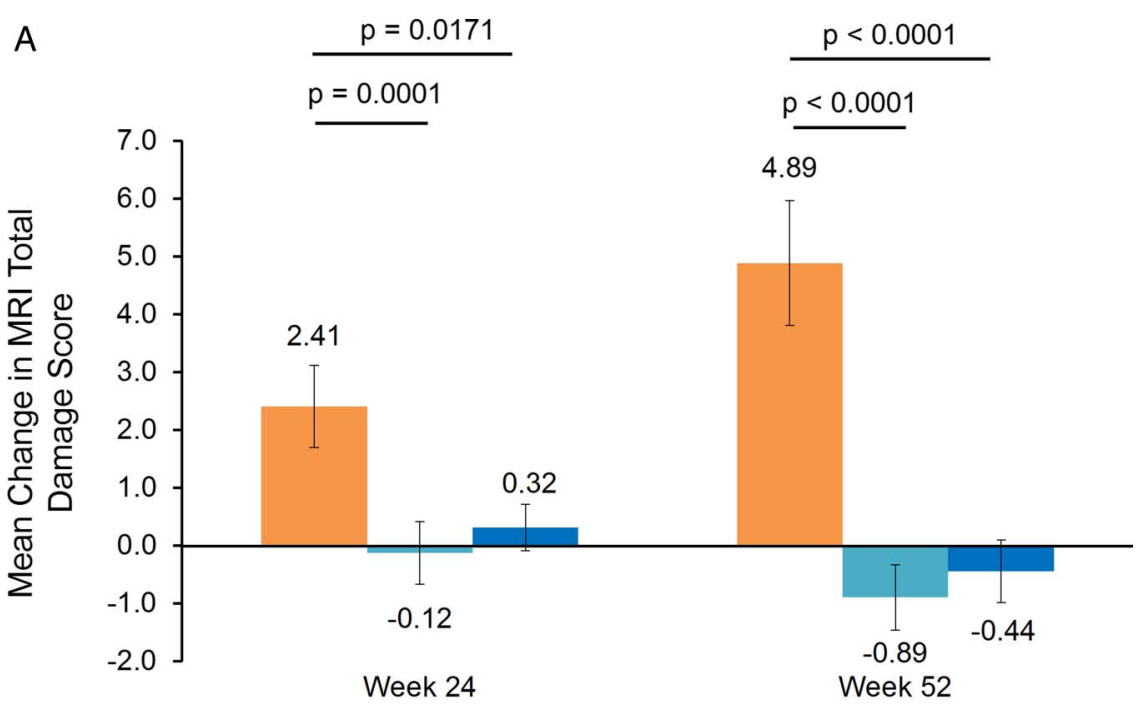

$\square$ Placebo $(n=63)$ Rituximab $500 m g(n=62)$ Rituximab $1000 m g(n=60)$

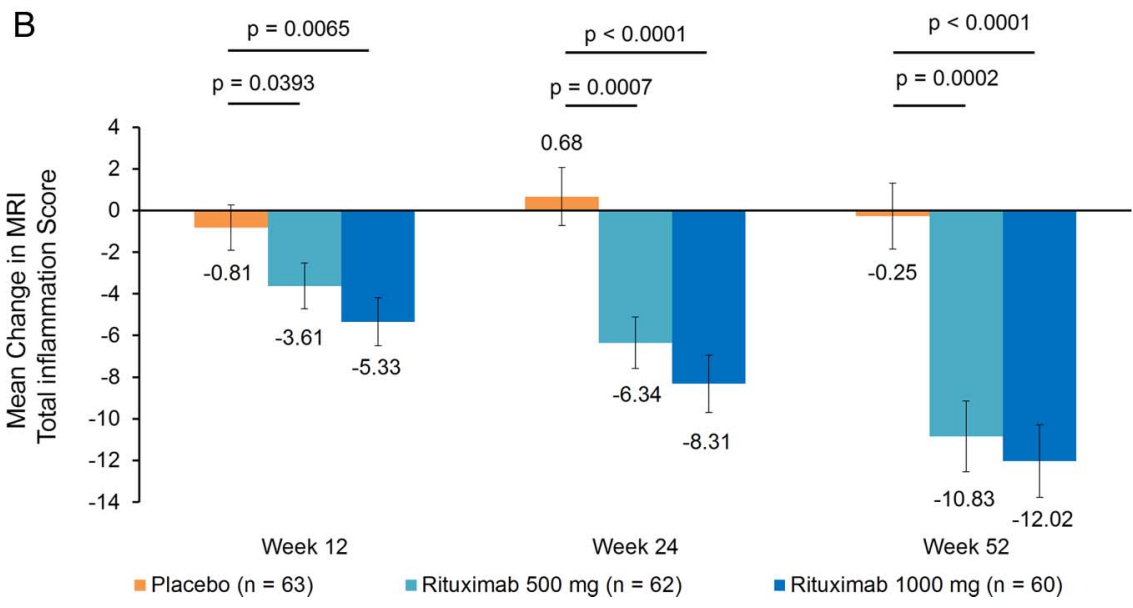

\section{MRI analysis}

The analysis of the primary end point showed significantly less progression in the mean RAMRIS erosion score at week 24 in patients treated with rituximab $1000 \mathrm{mg}$ compared with those treated with placebo (figure 1A). Similar results were observed at week 52. Significant differences were also observed between the rituximab 500-mg group and the placebo group at weeks 24 and 52. The mean change in RAMRIS erosion score at week 12 was not significantly different between either of the rituximab groups and the placebo group. The cumulative distribution plots revealed increased RAMRIS erosion score at week 24 in a greater proportion of patients in the placebo group than in either rituximab group (figure 1B).

Patients treated with rituximab $1000 \mathrm{mg}$ demonstrated a progressively greater decrease in mean RAMRIS synovitis score at weeks 12, 24 and 52, which was significantly greater than placebo at each time point (figure $2 \mathrm{~A}$ ). Patients receiving rituximab $500 \mathrm{mg}$ also showed a progressive decrease in the mean RAMRIS synovitis score at each time point; the decreases were numerically less than those in the rituximab 1000 mg-treated patients and were significantly different from those in the placebo-treated patients at weeks 24 and 52. The rituximab 1000 -mg group demonstrated significantly greater reductions in
RAMRIS osteitis scores compared with those in the placebo group at weeks 12, 24 and 52; similar results were observed in the rituximab 500-mg group at each time point (figure 2B). Mean cartilage loss scores based on CARLOS increased progressively at weeks 24 and 52 in patients treated with placebo, whereas patients treated with rituximab $1000 \mathrm{mg}$ showed significantly greater improvement compared with those who received placebo (figure 2C) at week 52; a statistically significant difference was not observed at week 24. Patients receiving rituximab $500 \mathrm{mg}$ demonstrated significantly less cartilage loss compared with those in the placebo group at weeks 24 and 52 .

Patients who received rituximab $1000 \mathrm{mg}$ demonstrated significantly better total damage scores compared with those in the placebo group at weeks 24 and 52 (figure 3A). Similar results were observed in the rituximab 500-mg group at weeks 24 and 52. Mean decreases in total inflammation score were significantly greater in the rituximab 1000-mg group compared with those in the placebo group as early as week 12 and were maintained through weeks 24 and 52 (figure 3B). Similar results were demonstrated in the rituximab 500-mg group.

The proportion of patients with no worsening of RAMRIS erosion score was significantly greater in the rituximab $1000-\mathrm{mg}$ group than in the placebo group at week 24 (table 2) and week 
Table 2 Summary of efficacy outcomes

\begin{tabular}{|c|c|c|c|c|c|}
\hline & Placebo+MTX $(n=63)$ & Rituximab 500 mg+MTX (n=62) & p Value* & Rituximab $1000 \mathrm{mg}+\mathrm{MTX}(\mathrm{n}=60)$ & p Valuet \\
\hline \multicolumn{6}{|c|}{ Patients with no newly eroded joints, \% } \\
\hline Week 24 & 55.6 & 77.4 & 0.011 & 73.3 & 0.045 \\
\hline Week 52 & 60.3 & 77.4 & 0.042 & 66.7 & 0.455 \\
\hline \multicolumn{6}{|c|}{ Patients with no progression of erosions, $\% \ddagger$} \\
\hline Week 24 & 33.3 & 50.0 & 0.055 & 51.7 & 0.039 \\
\hline Week 52 & 27.0 & 48.4 & 0.011 & 55.0 & $<0.001$ \\
\hline \multicolumn{6}{|c|}{ Mean change from baseline in Genant-modified Sharp radiographic erosion score } \\
\hline Week 24 & 0.62 & 0.21 & 0.049 & 0.14 & 0.097 \\
\hline Week 52 & 0.99 & 0.34 & 0.027 & 0.14 & 0.003 \\
\hline \multicolumn{6}{|c|}{ Mean change from baseline in Genant-modified Sharp radiographic JSN score } \\
\hline Week 24 & 0.14 & 0.09 & 0.286 & 0.16 & 0.796 \\
\hline Week 52 & 0.38 & 0.06 & 0.003 & 0.15 & 0.102 \\
\hline \multicolumn{6}{|c|}{ Mean change from baseline in total Genant-modified Sharp radiographic score } \\
\hline Week 24 & 0.76 & 0.31 & 0.034 & 0.30 & 0.310 \\
\hline Week 52 & 1.37 & 0.40 & 0.010 & 0.29 & 0.002 \\
\hline \multicolumn{6}{|c|}{ Mean change from baseline in DAS28-ESR } \\
\hline Week 24 & -0.85 & -1.69 & 0.007 & -1.64 & 0.277 \\
\hline Week 52 & -0.81 & -2.08 & $<0.001$ & -1.90 & 0.075 \\
\hline \multicolumn{6}{|c|}{ Patients with good EULAR response, \% } \\
\hline Week 24 & 19.0 & 29.0 & 0.017 & 35.0 & $<0.001$ \\
\hline Week 52 & 7.9 & 33.9 & $<0.001$ & 37.3 & $<0.001$ \\
\hline \multicolumn{6}{|c|}{ Patients with moderate EULAR response, \% } \\
\hline Week 24 & 22.2 & 37.1 & 0.0179 & 42.4 & $<0.0019$ \\
\hline Week 52 & 31.7 & 45.2 & $<0.0019$ & 49.2 & $<0.0019$ \\
\hline \multicolumn{6}{|c|}{ Change from baseline in HAQ-DI score } \\
\hline Week 24 & -0.19 & -0.425 & 0.026 & -0.44 & 0.778 \\
\hline Week 52 & -0.18 & -0.520 & 0.001 & -0.42 & 0.165 \\
\hline \multicolumn{6}{|c|}{ Patients achieving ACR20, \% } \\
\hline Week 24 & 28.6 & 51.6 & 0.003 & 51.7 & 0.006 \\
\hline Week 52 & 28.6 & 67.7 & $<0.001$ & 68.3 & $<0.001$ \\
\hline \multicolumn{6}{|c|}{ Patients achieving ACR50, \% } \\
\hline Week 24 & 11.1 & 24.2 & 0.050 & 26.7 & 0.013 \\
\hline Week 52 & 14.3 & 37.1 & 0.003 & 35.0 & 0.005 \\
\hline \multicolumn{6}{|c|}{ Patients achieving ACR70, \% } \\
\hline Week 24 & 1.6 & 11.3 & 0.036 & 8.3 & 0.085 \\
\hline Week 52 & 6.3 & 17.7 & 0.056 & 16.7 & 0.049 \\
\hline
\end{tabular}

52. Similar effects were observed for the rituximab 500-mg group, although the difference was only statistically significant at the 52-week time point.

\section{Radiographic analysis}

At week 52, the analysis of the total radiographic Genant-modified Sharp score revealed significantly greater inhibition of radiographic damage in patients in the rituximab 1000-mg and 500-mg groups compared with the placebo group, although the study was not powered for the comparison of radiographic end points. The changes in mean erosion score from baseline were significantly lower in the two active treatment groups compared with that in the control group, whereas the changes in mean joint-space-narrowing score were numerically lower in both rituximab groups, but statistically significantly so in the rituximab 500-mg group

\section{Clinical assessment}

Clinical efficacy outcomes are presented in table 2. At weeks 24 and 52, patients who received rituximab $500 \mathrm{mg}$ demonstrated significantly greater improvements in DAS28-ESR compared with those who received placebo; those who received $1000 \mathrm{mg}$ demonstrated numerically greater improvements in DAS28-ESR scores compared with those who received placebo, but the difference was not statistically significant at either time point. Significantly more patients in both rituximab groups achieved ACR20 and ACR50 compared with patients in the placebo group at weeks 24 and 52. However, ACR70 rates at weeks 24 and 52 in either rituximab group were not consistently improved compared with the rate in the placebo group. At weeks 24 and 52, significantly more patients in the rituximab $1000-\mathrm{mg}$ and 500-mg groups than in the placebo group had moderate or good EULAR responses. Significant improvements 
in HAQ-DI were seen in the rituximab 500-mg group at weeks 24 and 52. Numerical improvements were seen in the 1000-mg group compared with the placebo group at these time points, although these changes were not statistically significant.

\section{Safety}

The overall safety profiles were similar in both rituximab groups and are summarised in table 3. The incidence of AEs reported in the rituximab $1000-\mathrm{mg}$ and 500-mg groups was numerically lower than that reported in the placebo group, as was the incidence of serious AEs per 100 patient-years. The incidence of infections was numerically higher in both rituximab groups compared with that in the placebo group, as was the incidence of serious infections per 100 patient-years. One patient in the rituximab 500-mg group reported a serious soft tissue infection (of suspected bacterial origin), which was treated and resolved after 11 days. Two serious infections were reported in the rituximab 1000-mg group: bronchitis and omphalitis due to Escherichia coli. The two infections resolved following treatment. One endometrial carcinoma was reported in the rituximab 1000-mg group. No deaths and no life-threatening AEs were reported. Additional safety data are provided in online supplementary tables S2 and S3.

The incidence of infusion-related reactions decreased from $0 \%, 4.8 \%$ and $15.0 \%$ in the placebo, rituximab 500-mg and rituximab 1000-mg groups during the first course of rituximab to $0 \%, 0 \%$ and $5.0 \%$ during the second course, respectively. The maximum Common Toxicity Criteria for Adverse Events grade of the 13 total events was moderate.

Overall, no safety concerns were raised by the laboratory data. At week 24, five patients in the rituximab 500-mg group $(10.6 \%)$ and one in the rituximab 1000-mg group (3.8\%) were positive for human HACA. At week 52, only one patient $(2.8 \%)$ remained positive for HACA in the rituximab 500-mg group, whereas two patients $(6.5 \%)$ remained positive for HACA in the rituximab 1000-mg group.

\section{DISCUSSION}

In this placebo-controlled, double-blind, study, we used MRI to evaluate changes in structural damage and joint inflammation in MTX-IR patients with active RA who were biologicals-naive and received MTX plus either rituximab or placebo. The mean RAMRIS erosion score progressed in the placebo arm over 52 weeks at a rate of approximately 0.3 RAMRIS units per

\begin{tabular}{|c|c|c|c|}
\hline $\begin{array}{l}\text { Patients with event, } \\
\text { n (\%) }\end{array}$ & $\begin{array}{l}\text { Placebo+MTX } \\
(n=63)\end{array}$ & $\begin{array}{l}\text { Rituximab } \\
500 \mathrm{mg}+\mathrm{MTX} \\
(\mathrm{n}=62)\end{array}$ & $\begin{array}{l}\text { Rituximab } \\
1000 \mathrm{mg}+\mathrm{MTX} \\
(\mathrm{n}=60)\end{array}$ \\
\hline Any TEAE & $41(65.1)$ & $35(56.5)$ & $36(60.0)$ \\
\hline Mild & $20(31.7)$ & $17(27.4)$ & $13(21.7)$ \\
\hline Moderate & $17(27.0)$ & $18(29.0)$ & $19(31.7)$ \\
\hline Severe & $4(6.3)$ & - & $4(6.7)$ \\
\hline Treatment-related & $14(22.2)$ & $13(21.0)$ & $9(15.0)$ \\
\hline Any serious TEAE & $5(7.9)$ & $3(4.8)$ & $4(6.7)$ \\
\hline Events/100 PY & 12.0 & 4.9 & 6.9 \\
\hline Any infection & $16(25.4)$ & $25(40.3)$ & $27(45.0)$ \\
\hline Any serious infection & - & $1(1.6)$ & $3(5.0)$ \\
\hline Events/100 PY & 0.0 & 1.6 & 3.4 \\
\hline Death on study & - & - & - \\
\hline
\end{tabular}

month, consistent with the rates observed in the placebo arms of other randomised controlled trials of RA using MRI. ${ }^{17}$ Cartilage loss also progressed at 24 and 52 weeks in patients treated with placebo. Compared with placebo, rituximab $1000 \mathrm{mg}$ significantly reduced MRI erosion at 24 weeks (primary end point) and erosion and cartilage loss at 52 weeks. The rituximab 500-mg dose demonstrated improvements relative to placebo that were generally in the same range as observed with the higher rituximab dose, but the study was not powered to detect differences between the two doses in the observed range. The secondary end points of synovitis, osteitis, cartilage loss, total inflammation and total joint damage scores each improved significantly with rituximab compared with placebo as early as 12 weeks, and improved further at weeks 24 and 52. The proportions of patients with no joint damage progression, with improvements in synovitis and osteitis, and with moderate or good EULAR response were all significantly higher with rituximab than with placebo. For some disease activity indices, such as DAS28 and HAQ-DI, the rituximab 1000-mg dose demonstrated numerically positive trends, which were not always statistically significant.

Safety data were consistent with those previously reported for rituximab in biological-naive patients, ${ }^{3} 1819$ and no new safety signals were detected. AEs were predominantly mild, and few severe or serious AEs and no deaths were observed with treatment. No major differences between the safety profiles of the 1000-mg and 500-mg doses were observed.

These results are consistent with the findings of previous studies that used radiography to demonstrate inhibition of joint damage progression by rituximab, ${ }^{3} 520$ and may be explained by the inhibitory effect of rituximab treatment on osteoclastogenesis. ${ }^{21}$ Recent EULAR and ACR recommendations recognise the superiority of MRI to clinical examination at detecting joint inflammation and recommend the use of MRI to predict response to treatment. ${ }^{17}$

This study had several strengths. It is the first published report of MRI's ability to discriminate suppression of cartilage loss in a multicentre randomised controlled trial in RA. This is important because exclusion of the assessment of cartilage loss in prior clinical trials has been an obstacle to accepting MRI as a substitute for radiography in clinical trials. Previous studies have demonstrated that articular cartilage loss is at least as important as bone erosion in determining long-term disability in patients with $\mathrm{RA}^{22}$ and suppression of bone erosion does not always indicate that cartilage loss has also been suppressed. ${ }^{23}$ Inclusion of the assessment of cartilage loss in this study further allowed determination of total joint damage by MRI, analogous to the Total Sharp Score that is used in RA clinical trials to assess radiographic joint damage. A limitation of this study was that suppression of cartilage loss and radiographic outcomes were not measured at week 12, limiting the ability to compare cartilage loss against bone erosion or discriminate progression between the two imaging techniques. Additionally, although treatment effects in the rituximab $500-\mathrm{mg}$ and 1000-mg groups largely overlapped, in a few of the end points (particularly cartilage loss and joint-space narrowing), one or the other dosing arm did not reach statistical significance compared with placebo. Because this study was not powered to compare the two active treatment arms, additional analyses were not performed to explore this apparent discrepancy. Of note, in the IMAGE study, only the approved $2 \times 1000$-mg rituximab dosing group exhibited significant inhibition of radiographic progression compared with the placebo group, whereas those in the rituximab 500-mg group 
did not-a treatment effect that was robust to several analyses. ${ }^{3}$ Lastly, it is important to highlight that patients in this study were biological naive and DMARD-IR; therefore, the results cannot be extrapolated to patients with more progressive or refractory disease, such as TNF-IR patients.

In conclusion, this study demonstrated that rituximab significantly reduced erosion and cartilage loss at weeks 24 and 52 in MTX-IR patients with active RA. These changes were preceded by reductions in synovitis and osteitis, and explain radiographic evidence that rituximab+MTX prevents joint damage in patients with active RA. Our results suggest that MRI is a valuable tool for assessing inflammatory and structural damage in patients with established RA receiving rituximab.

\author{
Author affiliations \\ ${ }^{1}$ Spire Sciences, Inc., Boca Raton, Florida, USA \\ ${ }^{2}$ Leeds Institute of Rheumatic and Musculoskeletal Medicine, University of Leeds \& \\ NIHR Leeds Musculoskeletal Biomedical Research Unit, Leeds Teaching Hospitals \\ NHS Trust, Leeds, UK \\ ${ }^{3 *}$ Academic Medical Center/University of Amsterdam, Amsterdam, The Netherlands; \\ *Current address also: University of Cambridge, Cambridge, UK and \\ GlaxoSmithKline, Stevenage, UK \\ ${ }^{4}$ Copenhagen Center for Arthritis Research, Center for Rheumatology and Spine \\ Diseases, Glostrup Hospital. University of Copenhagen, Copenhagen, Denmark \\ ${ }^{5}$ Tallinn Central Hospital, Tallinn, Estonia \\ ${ }^{6}$ Hospital Universitario, Seville, Spain \\ 7 Charles University, Prague, Czech Republic \\ ${ }^{8} \mathrm{~F}$ Hoffmann-La Roche Ltd, Basel, Switzerland
}

Acknowledgements The authors thank all the investigators and patients involved in RA-SCORE.

Contributors $\mathrm{CP}$ conceived and designed the research, was involved in generating data at his clinical research site, assured data collection from the $\mathrm{NHIH}$ and analysed and interpreted the data. PE, PPT, MØ, KO, FNS and KP were involved in generating the data at their clinical research sites. JD contributed analysis tools and performed statistical analysis. CB analysed and interpreted the data and performed statistical analysis. LHG and AG analysed and interpreted the data. All authors were involved in writing the manuscript and approved it.

Funding This study was funded by Roche. Support for third-party writing assistance for this manuscript, furnished by Vivian Chen, PharmD, of Health Interactions based on the involvement and input of all authors, was provided by F Hoffmann-La Roche. All authors read and approved the final content of this manuscript.

Competing interests $\mathrm{CP}$ is a shareholder of Spire Sciences, Past Shareholder of Synarc (currently BioClinica), has undertaken clinical trials and/or provided expert advice for AbbVie, Acerta, Amgen, AstraZeneca, Bristol-Myers Squibb, Celgene, Eli Lilly and Company, Five Prime, Genentech, Janssen, Medimmune, Merck, Novartis, Pfizer, Rigel, Roche, Salix-Santarus, Sanofi, Samsung, UCB and Vertex, Employee of Spire Sciences, Past Employee of Synarc (currently BioClinica). PE has undertaken clinical trials and provided expert advice for Pfizer, MSD, Abbvie, Novartis, Roche and Bristol-Myers Squibb. PPT has served as a consultant for Roche/ Genentech and became an employee of GlaxoSmithKline after completion of this work. JD is a consultant for Abbott, Amgen, AstraZeneca, Biogen-Idec, Bristol-Myers Squibb, BioClinica, Celgene, Centocor, Core Lab Partners, Crescendo, Eli Lilly and Company, Genentech, Genzyme, Merck, Icon Medical Imaging, Novartis, Perceptive Informatics, Pfizer, Rigel, Roche, UCB, VirtualScopics, Wyeth, Employee of Spire Sciences, and Past Employee of Synarc. FNS has received consulting fees from: Roche, Pfizer, UCB, Abbott and Meiji Seika, Speakers bureau fees from: BMS Roche, Pfizer, UCB, Abbott and Meiji Seika. KP has received consulting fees and lecturer/ speaker fees from Roche, AbbVie, BMS, Pfizer, Amgen and MSD. M-AB, LHG, CB and $A G$ are employees of $F$ Hoffmann-La Roche.

Patient consent Obtained.

Ethics approval Independent Ethics Committee or Institutional Review Board.

Provenance and peer review Not commissioned; externally peer reviewed.

Open Access This is an Open Access article distributed in accordance with the Creative Commons Attribution Non Commercial (CC BY-NC 4.0) license, which permits others to distribute, remix, adapt, build upon this work non-commercially, and license their derivative works on different terms, provided the original work is properly cited and the use is non-commercial. See: http://creativecommons.org/ licenses/by-nc/4.0/

\section{REFERENCES}

1 Colebatch AN, Edwards CJ, Ostergaard M, et al. EULAR recommendations for the use of imaging of the joints in the clinical management of rheumatoid arthritis. Ann Rheum Dis 2013;72:804-14.

2 Cohen SB, Keystone E, Genovese MC, et al. Continued inhibition of structural damage over 2 years in patients with rheumatoid arthritis treated with rituximab in combination with methotrexate. Ann Rheum Dis 2010;69:1158-61.

3 Tak PP, Rigby W, Rubbert-Roth A, et al. Sustained inhibition of progressive joint damage with rituximab plus methotrexate in early active rheumatoid arthritis: 2-year results from the randomised controlled trial IMAGE. Ann Rheum Dis 2012;71:351-7.

4 Landewe RB, Boers M, Verhoeven AC, et al. COBRA combination therapy in patients with early rheumatoid arthritis: Long-term structural benefits of a brief intervention. Arthritis Rheum 2002;46:347-56.

5 Keystone EC, Cohen SB, Emery P, et al. Multiple courses of rituximab produce sustained clinical and radiographic efficacy and safety in patients with rheumatoid arthritis and an inadequate response to 1 or more tumor necrosis factor inhibitors: 5-year data from the REFLEX study. J Rheumatol 2012;39:2238-46.

6 Ostergaard M, Peterfy C, Conaghan $\mathrm{P}$, et al. OMERACT rheumatoid arthritis magnetic resonance imaging studies. core set of MRI acquisitions, joint pathology definitions, and the OMERACT RA-MRI scoring system. J Rheumatol 2003;30:1385-6.

7 American College of Rheumatology Rheumatoid Arthritis Clinical Trials Task Force Imaging Group and Outcome Measures in Rheumatology Magnetic Resonance Imaging Inflammatory Arthritis Working Group. Review: The utility of magnetic resonance imaging for assessing structural damage in randomized controlled trials in rheumatoid arthritis. Arthritis Rheum 2013;65:2513-23.

8 Tan YK, Conaghan PG. Imaging in rheumatoid arthritis. Best Pract Res Clin Rheumatol 2011;25:569-84

9 van de Sande MG, van der Leij C, Lavini C, et al. Characteristics of synovial inflammation in early arthritis analysed by pixel-by-pixel time-intensity curve shape analysis. Rheumatology (Oxford) 2012:51:1240-5.

10 Keystone E, Emery P, Peterfy CG, et al. Rituximab inhibits structural joint damage in patients with rheumatoid arthritis with an inadequate response to tumour necrosis factor inhibitor therapies. Ann Rheum Dis 2009;68:216-21.

11 Peterfy CG, Olech E, Dicarlo JC, et al. Monitoring cartilage loss in the hands and wrists in rheumatoid arthritis with magnetic resonance imaging in a multi-center clinical trial: IMPRESS (NCT00425932). Arthritis Res Ther 2013:15:R44.

12 Genovese MC, Kavanaugh A, Weinblatt ME, et al. An oral syk kinase inhibitor in the treatment of rheumatoid arthritis: a three-month randomized, placebo-controlled, phase II study in patients with active rheumatoid arthritis that did not respond to biologic agents. Arthritis Rheum 2011;63:337-45

13 Haavardsholm EA, Ostergaard M, Ejbjerg BJ, et al. Reliability and sensitivity to change of the OMERACT rheumatoid arthritis magnetic resonance imaging score in a multireader, longitudinal setting. Arthritis Rheum 2005;52:3860-7.

14 Ejbjerg B, Vestergaard A, Jacobsen $S$, et al. The sensitivity to change for destructive joint damage by the Sharp/van der Heijde $x$-ray scores and 2 different MRI approaches. Arthritis Rheum 2003;50(Suppl 9):5172.

15 Peterfy CG, DiCarlo JC, Olech E, et al. Evaluating joint-space narrowing and cartilage loss in rheumatoid arthritis by using MRI. Arthritis Res Ther 2012;14:R131.

16 Genant HK. Methods of assessing radiographic change in rheumatoid arthritis. Am J Med 1983;75:35-47.

17 Peterfy C, Ostergaard M, Conaghan PG. MRI comes of age in RA clinical trials. Ann Rheum Dis 2013;72:794-6.

18 Rubbert-Roth A, Tak PP, Zerbini C, et al. Efficacy and safety of various repeat treatment dosing regimens of rituximab in patients with active rheumatoid arthritis: Results of a phase III randomized study (MIRROR). Rheumatology (Oxford) 2010:49:1683-93.

19 Emery P, Fleischmann R, Filipowicz-Sosnowska A, et al. The efficacy and safety of rituximab in patients with active rheumatoid arthritis despite methotrexate treatment: results of a phase IIB randomized, double-blind, placebo-controlled, dose-ranging trial. Arthritis Rheum 2006;54:1390-400.

20 Cohen SB, Emery P, Greenwald MW, et al. Rituximab for rheumatoid arthritis refractory to anti-tumor necrosis factor therapy: results of a multicenter, randomized, double-blind, placebo-controlled, phase III trial evaluating primary efficacy and safety at twenty-four weeks. Arthritis Rheum 2006;54:2793-806.

21 Boumans MJ, Thurlings RM, Yeo L, et al. Rituximab abrogates joint destruction in rheumatoid arthritis by inhibiting osteoclastogenesis. Ann Rheum Dis 2012;71:108-13.

22 Smolen JS, van der Heijde DM, Aletaha $D$, et al. Progression of radiographic joint damage in rheumatoid arthritis: Independence of erosions and joint space narrowing. Ann Rheum Dis 2009;68:1535-40.

23 Cohen SB, Dore RK, Lane NE, et al. Denosumab treatment effects on structural damage, bone mineral density, and bone turnover in rheumatoid arthritis: a twelve-month, multicenter, randomized, double-blind, placebo-controlled, phase II clinical trial. Arthritis Rheum 2008;58:1299-309.

24 Bruynesteyn $\mathrm{K}$, Boers $\mathrm{M}$, Kostense $\mathrm{P}$, et al. Deciding on progression of joint damage in paired films of individual patients: smallest detectable difference or change. Ann Rheum Dis 2005:64:179-82. 